\title{
PENGARUH FINGER PAINTING TERHADAP PERKEMBANGAN MOTORIK HALUS ANAK USIA PRASEKOLAH DI TK SARTIKA I SUMURGENUK KECAMATAN BABAT LAMONGAN
}

\section{The Effect Of Finger painting To The Development Of Fine Motor On Preschool Children In Sartika I Sumurgenuk Kindergarten Babat Lamongan}

\author{
Lilis Maghfuroh, Kiki Chayaning Putri \\ STIKES Muhammadiyah Lamongan Jl.Raya Plalangan Plosowahyu Lamongan \\ Email : lilisahza99@gmail.com
}

\begin{abstract}
Preschoolers are children aged between 3-6 years. In this age, children are undergoing the process of growth and development that is very rapid and important for the process of further developments. In the initial survey, it was obtained a few preschool children experiencing fine motor development suspect. The purpose of this study was to determine the effect of finger painting on fine motor development of preschool children in Sartika 1 Sumurgenuk kindergarten Babat Lamongan.

This study used a pre-experimental design with the approach of one-group pre-post test design and statistical analysis procedures using the Wilcoxon Sign Rank Test with significance level of $p<0.05$ using SPSS 16.0. The population was all preschoolers in Sartika 1 Sumurgenuk kindergarten Babat Lamongan as many as 47 children and the sample was 42 children.

The results showed that almost all children have normal fine motor development after being given finger painting, with a value of $\mathrm{p}=0.001$ where $\mathrm{p}<0.05, \mathrm{H}_{1}$ was accepted meaning that there was influence of finger painting on the development of fine motor skills of preschoolers in Sartika 1 Sumurgenuk kindergarten Babat Lamongan.

It is hope that the educators of preschoolers can suggest finger painting activities as a method to develop and improve fine motor development of children.
\end{abstract}

Keywords: Finger painting, fine motor development, Preschool Children.

\begin{abstract}
ABSTRAK
Anak usia prasekolah merupakan anak yang berusia antara 3-6 tahun. Pada usia ini, anak sedang menjalani proses pertumbuhan dan perkembangan yang sangat pesat dan penting bagi proses perkembangan selanjutnya. Pada survey awal didapatkan sebagian kecil anak prasekolah mengalami perkembangan motorik halus suspek. Tujuan penelitian ini untuk mengetahui pengaruh finger painting terhadap perkembangan motorik halus anak usia prasekolah di TK Sartika I Sumurgenuk Kecamatan Babat Lamongan.

Penelitian ini menggunakan metode pra-eksperiment design dengan pendekatan one-group pra-post test design dan prosedur analisis statistic menggunakan Uji Wilcoxon Sign Rank Test dengan tingkat kemaknaan $\mathrm{p}<0,05$ menggunakan program SPSS 16.0. Populasi penelitian adalah seluruh anak prasekolah di TK Sartika I Sumurgenuk Kecamatan Babat Lamongan sebanyak 47 anak dan besar sampel 42 anak.

Hasil penelitian menunjukkan hampir seluruhnya anak memiliki perkembangan motorik halus normal setelah diberikan finger painting, dengan nilai $\mathrm{p}=0,001$ dimana $\mathrm{p}<0,05$ maka
\end{abstract}


$\mathrm{H}_{1}$ diterima artinya ada pengaruh finger painting terhadap perkembangan motorik halus anak usia prasekolah di TK Sartika I Sumurgenuk Kecamatan Babat Lamongan.

Melihat hasil penelitian di atas hendaknya para pendidik anak usia prasekolah dapat menjadikan kegiatan finger painting sebagai metode untuk mengembangkan dan meningkatkan perkembangan motorik halus anak.

Kata kunci : Finger painting, Perkembangan motorik halus, Anak Prasekolah.

\section{PENDAHULUAN}

Pada umumnya, proses tahapan perkembangan setiap anak sama, yaitu merupakan hasil dari proses pematangan. Tetapi dalam pencapaiannya, setiap anak memiliki kecepatan yang berbeda. Tahapan tumbuh kembang anak dibagi menjadi beberapa diantaranya adalah masa pranatal (dari konsepsi sampai lahir), masa bayi (dari usia 0-1 tahun), masa anak dini (usia 1-3 tahun), masa prasekolah (usia 3-6 tahun) dan masa sekolah (usia 6-18/20 tahun) (Soetjiningsih, 2013).

Anak usia prasekolah merupakan anak yang berusia antara 3-6 tahun. Dalam usia ini anak umumnya mengikuti program anak (3-5 tahun) dan kelompok bermain (usia 3 tahun), sedangkan pada usia 4-6 tahun biasanya mereka mengikuti program taman kanak-kanak (Patmonodewo, 2008). Anak usia ini diharapkan telah mampu menguasai beberapa keterampilan yang menuntut kemampuan motorik halus, seperti menggunakan gunting dengan baik meskipun belum lurus dalam menggunting, mengikat tali sepatu, mewarnai dengan rapi, dan lain-lain sesuai dengan perkembangan motorik halus yang harus dicapainya, maka kegiatan-kegiatan yang dilakukan pada anak usia dini harus diarahkan untuk meningkatkan keterampilannya dalam hal-hal tersebut. Hal ini sangat penting karena hanya kesempatan dan latihan secara terus menerus yang akan dapat meningkatkan keterampilan anak dalam melakukan kegiatan-kegiatan yang menuntut gerakan motorik halus (Sujiono, 2009).

Perkembangan motorik halus berhubungan dengan kemampuan anak untuk mengamati sesuatu, melakukan gerakan yang melibatkan bagian tubuh tertentu saja, dengan bantuan otot-otot kecil serta memerlukan koordinasi yang cermat dari mata, tangan dan jari. Keterampilan motorik halus merupakan koordinasi halus pada otot-otot kecil yang memainkan suatu peran utama (Soetjiningsih, Tumbuh Kembang Anak. Edisi 2, 2013).

Penelitian yang dilakukan oleh Partiyem, 2014 pada kelompok B PAUD Istiqomah di Sumber Bening Kecamatan Selupu Rejang Bengkulu terdapat $45 \%$ anak belum mampu dalam aktivitas motorik halusnya (memegang pensil dengan benar, memegang gunting dan menggunting mengikuti bentuk pola, serta memegang crayon) dan anak di TK Dharma Wanita Desa Gadingwatu Kecamatan Menganti Kabupaten Gresik, kemampuan motorik halusnya dinilai masih kurang yaitu dari 22 anak sebagian besar belum mampu untuk mengerakkan jari tangan dengan luwes maupun kemampuan untuk menggengam dan memegang benda dengan baik. (Afiffudin \& Khotimah, 2014)

Berdasarkan studi pendahuluan yang dilakukan oleh peneliti di Taman Kanakkanak Sartika I Sumurgenuk Kecamatan Babat Lamongan pada tanggal 18 Nopember 2015, peneliti mengambil 10 anak secara acak dari 47 anak, didapatkan $6(60 \%)$ anak normal dan $4(40 \%)$ suspek yang menandakan masih adanya perkembangan motorik halus anak yang tidak sesuai dengan usia pertumbuhan.

Menurut Soetjiningsih (2013), kemampuan motorik halus dipengaruhi oleh matangnya fungsi motorik, dan koordinasi neuromuskular yang baik, fungsi visual yang akurat dan kemampuan intelek nonverbal. Dan perbedaan perkembangan motorik halus anak dipengaruhi oleh pembawaannya dan stimulasi yang didapatkannya. Lingkungan (orang tua) 
mempunyai pengaruh yang sangat besar dalam kecerdasan motorik halusnya. Faktor tersebut mampu meningkatkan ataupun menurunkan taraf kecerdasannya, terutama pada masa-masa awal kehidupannya. Karakteristik anak dengan kecerdasan motorik halus baik adalah mudah dan lebih baik dalam melakukan beberapa aktivitas seperti memakai baju, menggunting, menggambar, dan menulis. Sedangkan dampak yang disebabkan oleh keterlambatan perkembangan motorik halus adalah kesulitan dalam beberapa aktivitas seperti yang dijelaskan pada karakteristik anak dengan kecerdasan motorik halus baik (Fida \& Maya, 2012).

Untuk mengembangkan keterampilan motorik halus sekaligus menanggulangi rasa bosan pada anak, dapat diberikan stimulasi/rangsangan berupa kegiatan yang menarik agar anak dapat belajar dengan bersemangat. Kegiatan yang dapat dilakukan adalah bermain puzzle, memotong, membuat cerita gambar tempel, menempel gambar, menjahit, menggambar/menulis, menghitung, membuat gambar tempel, mencampur warna, dan menggambar dengan jari (finger painting) (Sulistyawati, 2014).

Menurut Pamadi (2008), finger painting adalah teknik melukis secara langsung tanpa menggunakan bantuan alat, anak dapat mengganti kuas dengan jari-jari tangannya secara langsung. Di dalam kegiatan finger painting, anak dengan bebas menuangkan imajinasi yang akan diwujudkannya. Menurut B.E.F Montolalu (2009), finger painting dapat mengembangkan ekspresi melalui media lukis dengan gerakan tangan, mengembangkan fantasi, imajinasi dan kreasi, melatih otot-otot tangan/jari, koordinasi otot dan mata, melatih kecakapan mengkombinasikan warna, memupuk perasaan terhadap gerakan tangan, dan memupuk keindahan.

Kegiatan finger painting dapat digunakan sebagai kegiatan alternatif guna menggantikan krayon agar kegiatan menggambar lebih menarik untuk anak. Finger painting dapat membantu anak mengembangkan motorik halusnya karena kegiatan ini dapat melatih koordinasi mata dan tangan. Berdasarkan hal tersebut, maka perlu dilakukan penelitian guna mengetahui pengaruh finger painting terhadap perkembangan motorik halus pada anak di TK Sartika I Sumurgenuk Kecamatan Babat.

\section{METODE PENELITIAN}

Penelitian ini termasuk jenis penelitian yang menggunakan desain penelitian praeksperimental yaitu mencari keterkaitan antara dua variabel atau lebih. Pendekatan yang digunakan dalam penelitian ini adalah one-group pra-post test design yaitu jenis penelitian yang mengungkap hubungan sebab akibat dengan cara melibatkan satu kelompok subjek. Kelompok subjek diobservasi sebelum dilakukan intervensi, kemudian diobservasi lagi setelah diintervensi (Nursalam, 2014). Populasi penelitian adalah seluruh anak prasekolah di TK Sartika I Sumurgenuk Kecamatan Babat Lamongan sebanyak 47 anak dan besar sampel 42 anak.

\section{HASIL PENELITIAN}

\section{Data Umum}

\section{1) Jenis kelamin anak}

Tabel 1 Distribusi Frekuensi Karakteristik Anak Berdasarkan Jenis Kelamin Di TK Sartika I Sumurgenuk Kecamatan Babat Lamongan Tahun 2016.

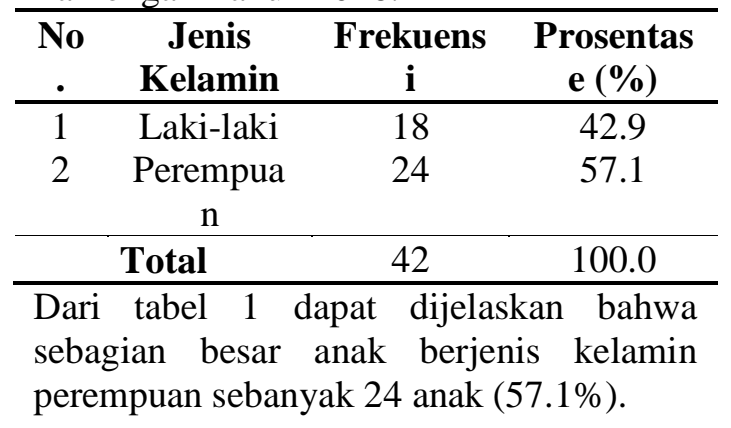

\section{2) Umur anak}

Tabel 2 Distribusi Frekuensi Karakteristik Anak Berdasarkan Umur Di TK Sartika I Sumurgenuk Kecamatan Babat Lamongan Tahun 2016.

\begin{tabular}{cccc}
\hline No. & $\begin{array}{c}\text { Umur } \\
\text { (bulan) }\end{array}$ & Frekuensi & $\begin{array}{c}\text { Prosentase } \\
(\%)\end{array}$ \\
\hline 1 & $48-54$ & 9 & 21.4 \\
\hline
\end{tabular}




\begin{tabular}{|c|c|c|c|}
\hline 2 & $55-60$ & 15 & 35.7 \\
\hline 3 & $61-66$ & 11 & 26.2 \\
\hline 4 & $67-72$ & 7 & 16.7 \\
\hline \multicolumn{2}{|c|}{ Total } & 42 & 100.0 \\
\hline \multicolumn{4}{|c|}{$\begin{array}{l}\text { Dari tabel } 2 \text { dapat dijelaskan bahwa } \\
\text { sebagian besar anak berumur } 55-60 \text { bulan } \\
\text { sebanyak } 15 \text { anak }(35.7 \%) \text { dan sebagian } \\
\text { kecil anak berumur } 67-72 \text { bulan sebanyak } \\
7 \text { anak }(16.7 \%) \text {. }\end{array}$} \\
\hline
\end{tabular}

\section{3) Umur Orang Tua}

Tabel 3 Distribusi Frekuensi Karakteristik Orang Tua Berdasarkan Umur Di TK Sartika I Sumurgenuk Kecamatan Babat Lamongan Tahun 2016.

\begin{tabular}{cccc}
\hline No. & $\begin{array}{c}\text { Umur } \\
\text { (Tahun) }\end{array}$ & Frekuensi & $\begin{array}{c}\text { Prosentase } \\
(\mathbf{\%})\end{array}$ \\
\hline 1 & $21-35$ & 27 & 64.3 \\
2 & $>35$ tahun & 15 & 35.7 \\
\hline & Total & 42 & 100.0 \\
\hline
\end{tabular}

Dari data 3 menunjukkan bahwa sebagian besar orang tua berumur antara 21 sampai 35 tahun yaitu sebanyak 27 orang (64.3\%).

\section{4) Pendidikan Orang Tua}

Tabel 4 Distribusi Frekuensi Karakteristik Orang Tua Berdasarkan Pendidikan Di TK Sartika I Sumurgenuk Kecamatan Babat Lamongan Tahun 2016.

\begin{tabular}{clcc}
\hline $\begin{array}{c}\text { No } \\
\text {. }\end{array}$ & $\begin{array}{c}\text { Pendidika } \\
\text { n }\end{array}$ & $\begin{array}{c}\text { Frekuens } \\
\mathbf{i}\end{array}$ & $\begin{array}{c}\text { Prosentas } \\
\mathbf{e}(\boldsymbol{\%})\end{array}$ \\
\hline 1 & SD & 8 & 19.0 \\
2 & SMP & 21 & 50.0 \\
3 & SMA & 12 & 28.6 \\
4 & Sarjana & 1 & 2.4 \\
\hline & Total & 42 & 100.0 \\
\hline
\end{tabular}

Dari tabel 4 menunjukkan bahwa sebagian orang tua memiliki latar belakang pendidikan terakhir Sekolah Menengah Pertama (SMP) sebanyak 21 orang (50\%) dan sebagian kecil memiliki latar belakang pendidikan terakhir Sarjana (S1) sebanyak 1 orang $(2.4 \%)$.

\section{5) Pekerjaan Orang Tua}

Tabel 5 Distribusi Frekuensi Karakteristik Orang Tua Berdasarkan Pekerjaan Di TK
Sartika I Sumurgenuk Kecamatan Babat Lamongan Tahun 2016.

\begin{tabular}{clcc}
\hline No. & Pekerjaan & Frekuensi & $\begin{array}{c}\text { Prosentase } \\
(\%)\end{array}$ \\
\hline 1 & Ibu Rumah & 38 & 90.5 \\
& Tangga & 4 & 9.5 \\
\hline & Wiraswasta & 42 & 100.0 \\
\hline
\end{tabular}

Dari tabel 5 menunjukkan bahwa hampir seluruhnya orang tua memiliki latar belakang perkerjaan ibu rumah tangga sebanyak 38 orang $(90.5 \%)$.

\section{Data Khusus}

1) Perkembangan motorik halus anak sebelum diberikan kegiatan finger painting.

Tabel 6 Distribusi Perkembangan Motorik Halus Anak Sebelum Diberikan Kegiatan Finger painting Pada Anak Usia 3-6 Tahun di TK Sartika I Sumurgenuk Kecamatan Babat Lamongan Tahun 2016.

\begin{tabular}{cccc}
\hline $\begin{array}{c}\text { N } \\
\text { o. }\end{array}$ & $\begin{array}{c}\text { Perkembangan } \\
\text { Motorik Halus }\end{array}$ & Frekuensi & $\begin{array}{c}\text { Prosentas } \\
\text { e (\%) }\end{array}$ \\
\hline 1 & Normal & 29 & 69.0 \\
2 & Suspek & 13 & 31.0 \\
\hline & Total & 42 & 100.0 \\
\hline
\end{tabular}

Berdasarkan tabel 6 dapat dijelaskan bahwa perkembangan motorik halus anak usia prasekolah di TK Sartika I Sumurgenuk Kecamatan Babat Lamongan sebelum diberikan kegiatan finger painting sebagian besar sebanyak 29 anak (69\%) normal.

2) Perkembangan motorik halus anak setelah diberikan kegiatan finger painting.

Tabel 7 Distribusi Perkembangan Motorik Halus Anak Setelah Diberikan Kegiatan Finger painting Pada Anak Usia 3-6 Tahun di TK Sartika I Sumurgenuk Kecamatan Babat Lamongan Tahun 2016.

\begin{tabular}{|c|c|c|c|}
\hline $\begin{array}{l}\mathbf{N} \\
\mathbf{o .}\end{array}$ & $\begin{array}{l}\text { Perkembangan } \\
\text { Motorik Halus } \\
\end{array}$ & Frekuensi & $\begin{array}{c}\text { Prosentase } \\
(\%)\end{array}$ \\
\hline 1 & Normal & 40 & 95.2 \\
\hline 2 & Suspek & 2 & 4.8 \\
\hline & Total & 42 & 100.0 \\
\hline
\end{tabular}

Berdasarkan tabel 7 dapat dijelaskan bahwa perkembangan motorik halus anak 
usia prasekolah di TK Sartika I Sumurgenuk Kecamatan Babat Lamongan setelah diberikan kegiatan finger painting hampir seluruhnya sebanyak 40 anak (95.2\%) normal.

3) Pengaruh Perkembangan Motorik Halus Anak Menggunakan Finger painting.

Tabel 8 Distribusi Pengaruh

Perkembangan Motorik Halus

Menggunakan Finger painting Pada

Anak Usia 3-6 Tahun di TK Sartika I

Sumurgenuk Kecamatan Babat

Lamongan Tahun 2016.

\section{PEMBAHASAN}

1) Perkembangan motorik halus anak sebelum diberikan kegiatan finger painting.

Berdasarkan tabel 6 dapat dijelaskan bahwa kemampuan motorik halus anak TK Sartika I Sumurgenuk Kecamatan Babat Lamongan sebelum diberikan finger painting sebagian besar normal sebanyak 29 anak (69\%).

Dari fakta di atas dapat dijelaskan bahwa perkembangan motorik halus anak sebagian besar normal. Perkembangan motorik halus dipengaruhi oleh stimulus

Motorik Halus Anak Prasekolah Sesudah kesempatan untuk menggerakkan anggota Anak

Prasekolah Diberikan Finger

badannya yang ditunjukkan oleh

$\begin{array}{lllllll}\text { Diberikan } & \Sigma & \% & \Sigma & \% & \boldsymbol{N}\end{array}$ sesuai dengan usianya.

$\begin{array}{lllllll}\text { Finger painting } & & & & & & \end{array}$ pini tersebut sejalan dengan teori yang

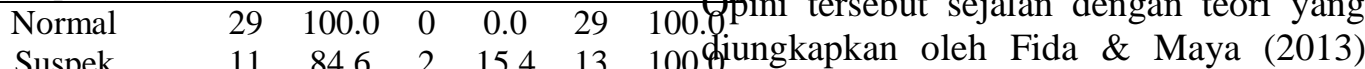

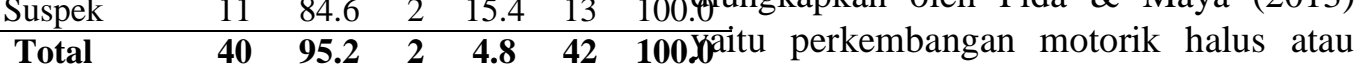
$\mathbf{Z}=\mathbf{- 3 . 3 1 7 ^ { \mathbf { a } }} \quad \mathbf{p}=\mathbf{0 , 0 0 1} \quad$ sebagian anggota tubuh tertentu, yang

Berdasarkan tabel 8 di atas dapat dijelaskan bahwa dari 29 anak yang perkembangan motorik halusnya normal sebelum diberikan finger painting, dimana setelah diberikan finger painting perkembangan motorik halus seluruhnya 29 anak dan dari 13 anak yang perkembangan motorik halusnya suspek sebelum diberikan finger painting, dimana setelah diberikan finger painting sebagian besar motorik halusnya normal sebesar 11 anak $(84.6 \%)$ dan sebagian kecil suspek sebesar 2 anak (15.4\%).

Berdasarkan hasil pengujian dengan uji wilcoxon dengan SPSS, didapat nilai $\mathrm{Z}$ sebesar -3.317. Dari tabel $\mathrm{Z}$ untuk angka $Z_{\text {hitung }}=3.317$ didapat angka kumulatif sebesar 0,9995. Hal ini berarti probabilitas adalah 1-0,9995 atau 0,0005. Karena uji 2 sisi, maka probabilitas (asymp. sig.) adalah 0.001. Hasil $\mathrm{Z}_{\text {hitung }}$ menjauhi angka kritiz $\mathrm{Z} \pm 1,96$, maka $\mathrm{H}_{0}$ ditolak, artinya terdapat pengaruh finger painting terhadap perkembangan motorik halus pada anak usia prasekolah di TK Sartika I Sumurgenuk Kecamatan Babat Lamongan. dipengaruhi oleh kesempatan untuk belajar dan berlatih. Dengan ungkapan lain, kemampuan motorik halus ialah kemampuan yang berhubungan dengan keterampilan fisik yang melibatkan otot kecil serta koordinasi mata dan tangan.

Berdasarkan observasi sebelum diberikan finger painting yang dilakukan juga di TK Santa Maria Singaraja Kabupaten Buleleng masih dirasakan kurang dalam mengkoordinasikan mata dan tangan seperti menggunting, memegang pensil dan menarik garis dengan benar. Dalam kegiatan menggunting anak masih terlihat lemas menggerakkan antara ibu jari dan telunjuk, cara menggunting juga belum begitu benar, sedangkan kegiatan menarik garis dengan memegang pensil antara ibu jari dan telunjuk sama halnya dengan kegiatan menggunting, kegiatan menarik garis dengan menggunakan pensil anak juga kurang bisa dalam mengontrol koordinasi tangan dan mata, tangan anakanak masih terlihat lemas dan kaku (Astria, Sulastri, \& Magta, 2015). 


\section{2) Perkembangan motorik halus anak setelah diberikan kegiatan finger painting.}

Berdasarkan tabel 7 dapat diketahui bahwa setelah diberikan kegiatan finger painting hampir seluruhnya atau 40 anak $(95.2 \%)$ normal. Dengan melihat data tersebut, maka secara umum dapat dikatakan bahwa perkembangan motorik halus anak normal. Hal tersebut dipengaruhi oleh kesempatan untuk belajar dan rangsangan yang mudah dan tepat yang diberikan untuk meningkatkan perkembangan motorik halus anak, salah satunya melalui finger painting. Dengan kegiatan ini anak-anak dapat memainan bubur warna di atas kertas dengan menggunakan gerakan jari-jari mereka secara langsung.

Opini tersebut didukung oleh teori B.E.F Montolalu (2009), finger painting dapat mengembangkan ekspresi melalui media lukis dengan gerakan tangan, mengembangkan fantasi, imajinasi dan kreasi, melatih otot-otot tangan/jari, koordinasi otot dan mata, melatih kecakapan mengkombinasikan warna, memupuk perasaan terhadap gerakan tangan, dan memupuk keindahan. Kegiatan ini bermanfaat bagi perkembangan anak, yaitu melatih kemampuan motorik halus anak karena jari-jari anak akan bergerak dan bergesekan dengan cat dan media lukisnya, mengembangkan dan mengenalkan berbagai warna dan bentuk, meningkatkan daya imajinasi dan kreativitas anak, meningkatkan koordinasi mata dan tangan, melatih konsentrasi, serta dapat dijadikan sebagai media mengekspresikan emosi anak (Listyowati \& Sugiyanto, 2014).

Berdasarkan hasil penelitian yang dilakukan oleh Retno Marheny 2012, anak didik pos Paud Mekar Lestari kelompok usia 3-4 tahun yang kemampuan motorik halusnya bagus melalui kegiatan finger painting semula hanya 3 dari 10 anak atau $30 \%$ saja, namun setelah diadakan tindakan pada siklus I anak yang kemampuan motorik halusnya bagus meningkat menadi 6 anak atau $60 \%$, jadi ada peningkatan sebanyak 3 atau $30 \%$. Selain mempengaruhi perkembangan motorik halus anak, kegiatan finger painting juga dapat mempengaruhi kreativitas anak seperti penelitian yang dilakukan oleh Lia Listiana, 2012 bahwa permainan finger painting berpengaruh terhadap kreativitas anak usia dini kelompok B di PAUD Melati Desa Sawahan Kecamatan Panggul Kabupaten Trenggalek dan penelitian yang telah dilakukan oleh Rifka Gayatri, 2013 bahwa finger painting berperan terhadap kemampuan anak mengenal konsep warna di kelompok B TK Nurul Islam Lambara, karena melalui finger painting kemampuan anak mengenal warna secara konsep dapat berkembang dengan baik diantaranya kemampuan menyebutkan macam-macam warna meningkat dari $26,67 \%$ menjadi $73,77 \%$, mengelompokkan macam-macam warna meningkat dari $20 \%$ menjadi $60 \%$, dan mengenal simbol-simbol warna meningkat dari $20 \%$ menjadi $40 \%$.

\section{3) Pengaruh Perkembangan Motorik Halus Anak Menggunakan Finger painting.}

Berdasarkan tabel 8 di atas dapat dijelaskan bahwa dari 29 anak yang perkembangan motorik halusnya normal sebelum diberikan finger painting, dimana setelah diberikan finger painting perkembangan motorik halus seluruhnya 29 anak dan dari 13 anak yang perkembangan motorik halusnya suspek sebelum diberikan finger painting, dimana setelah diberikan finger painting sebagian besar motorik halusnya normal sebesar 11 anak $(84.6 \%)$ dan sebagian kecil suspek sebesar 2 anak (15.4\%). Masih adanya sebagian kecil anak dengan perkembangan motorik halus suspek setelah diberikan finger painting diakibatkan oleh kemauan atau antusias anak untuk melakukan kegiatan kurang dan dapat juga karena mereka mudah bosan dengan kegiatan yang mereka lakukan.

Berdasarkan hasil pengujian dengan uji wilcoxon dengan SPSS, didapat nilai $\mathrm{Z}$ sebesar -3.317. Dari tabel Z untuk angka $\mathrm{Z}_{\text {hitung }}=3.317$ didapat angka kumulatif sebesar 0,9995. Hal ini berarti probabilitas adalah 1-0,9995 atau 0,0005. Karena uji 2 sisi, maka probabilitas (asymp. sig.) adalah 
0.001. Hasil $\mathrm{Z}_{\text {hitung }}$ menjauhi angka kritiz $\mathrm{Z}$ $\pm 1,96$, maka $\mathrm{H}_{0}$ ditolak atau $\mathrm{H}_{1}$ diterima, artinya terdapat pengaruh finger painting terhadap perkembangan motorik halus pada anak usia prasekolah di TK Sartika I Sumurgenuk Kecamatan Babat Lamongan. Kajian di atas menunjukkan bahwa kegiatan finger painting yang diberikan pada anak usia prasekolah di TK Sartika I Sumurgenuk Kecamatan Babat Lamongan memiliki pengaruh yang signifikan terhadap perkembangan motorik halus anak, sehingga dapat dikatakan pula bahwa kegiatan finger painting ini dapat diterapkan untuk membantu anak usia prasekolah dalam mengembangkan motorik halusnya. Dengan demikian finger painting bisa meningkatkan perkembangan motorik halus anak usia prasekolah di Taman Kanak-kanak Sartika I Sumurgenuk Kecamatan Babat Lamongan.

Opini tersebut didukung oleh teori yang dikemukakan oleh Listyowati \& Sugiyanto (2014) bahwa kegiatan finger painting dapat membantu anak dalam mengembangkan motorik halusnya karena kegiatan ini dapat melatih koordinasi mata dan tangan. Finger painting atau menggambar dengan jari merupakan teknik melukis dengan jari tangan secara langsung tanpa menggunakan bantuan alat. Jenis kegiatan ini dilakukan dengan cara menggoreskan adonan warna (bubur warna) menggunakan jari tangan di atas bidang gambar. Kegiatan finger painting digunakan sebagai kegiatan alternatif guna menggantikan krayon agar kegiatan menggambar lebih menarik untuk anak.

Didukung penelitian yang dilakukan oleh Laili Vitamami, 2013, menunjukkan bahwa bermain finger painting dapat meningkatkan kemampuan motorik halus anak di kelompok A2 RA BABUSSALAM Krian Sidoarjo tahun ajaran 2012-2013.

\section{KESIMPULAN}

Berdasarkan hasil penelitian dan pembahasan dapat diambil kesimpulan bahwa :

1. Perkembangan motorik halus anak di TK Sartika I Sumurgenuk Kecamatan Babat Lamongan sebelum diberikan kegiatan finger painting terdapat 29 anak (69\%) atau sebagian besar normal.

2. Perkembangan motorik halus anak setelah diberikan kegiatan finger painting hampir seluruhnya perkembangan motorik halus anak usia prasekolah (3-6 tahun) di TK Sartika I Sumurgenuk Kecamatan Babat Lamongan normal sebanyak 40 anak $(95.2 \%)$.

3. Terdapat pengaruh finger painting terhadap perkembangan motorik halus anak prasekolah (3-6 tahun) di TK Sartika I Sumurgenuk Kecamatan Babat Lamongan.

\section{SARAN}

Berdasarkan hasil yang ditemukan dari keterbatasan penelitian, maka yang dapat menjadi saran adalah sebagai berikut:

\section{Bagi Akademis}

Dari hasil penelitian ini diharapkan dapat memberikan sumbangan bagi ilmu pengetahuan khususnya cara penatalaksanaan kejadian perkembangan motorik halus suspect pada anak pra sekolah (3-6 tahun) sebagai sarana pembanding bagi dunia ilmu pengetahuan dalam memperkaya informasi tentang terapi finger painting terhadap perkembangan motorik halus.

\section{Bagi Praktisi}

\section{(1) Bagi Pemerintah}

Dengan adanya hasil penelitian ini angka kejadian perkembangan motorik halus yang tidak sesuai dengan usia perkembangan (suspek) pada anak dapat menurun.

(2) Bagi Profesi Keperawatan

Hendaknya setiap petugas kesehatan harus mengetahui faktor-faktor yang berpotensi untuk menimbulkan perkembangan motorik halus yang tidak sesuai dengan usia perkembangan (suspek) yang mana apabila ditemukan faktor resiko tersebut dapat dilakukan terapi finger painting pada anak pra sekolah (3-6 tahun).

(3) Bagi Peneliti Selanjutnya

Diharapkan dapat menggunakan metode penelitian yang lain dengan menghubungkan faktor-faktor lain yang 
mempengaruhi terjadinya perkembangan motorik halus yang tidak sesuai dengan usia perkembangan (suspect), menambah populasi dan sampel agar hasinya lebih valid dan representative, serta variabel yang diteliti harus homogen.

(4) Bagi pendidik

Diharapkan kegiatan ini dapat digunakan sebagai metode untuk mengembangkan dan meningkatkan perkembangan motorik halus anak usia prasekolah.

\section{DAFTAR PUSTAKA}

Afiffudin, \& Khotimah, N. (2014). Pengaruh Kegiatan Seni Finger painting Terhadap Kemampuan Motorik Halus Anak. 1-2. Diakses tanggal 3 Juni 2016

Astria, N., Sulastri, M., \& Magta, M. (2015). Penerapan Metode Bermain Melalui Kegiatan Finger painting Untuk Meningkatkan Kemampuan Motorik Halus. 3. Diakses tanggal 3 Juni 2016.

B.E.F. Montolalu. (2009). Bermain dan Permainan Anak. Jakarta: Universitas Terbuka.

Fida, \& Maya. (2012). Pengantar Ilmu Kesehatan Anak. Jogjakarta: DMedika.

Rifka Gayatri, (2013). Peranan Finger Painting Terhadap Kemampuan Anak Mengenal Konsep Warna Di Kelompok $B \quad T K$ Nurul Islam Lambara Kecamatan Tawaeli. Diakses tanggal 4 Juni 2016

Lia Listiana, \& Simatupang, N. D. (2012). Pengaruh Permainan Finger Painting Terhadap Kreatifitas Anak Usia Dini Kelompok B Di PAUD
Melati. 5. Diakses tanggal 4 Juni 2016

Listyowati, A., \& Sugiyanto. (2014). Finger painting. Jakarta: Erlangga.

Retno Marheny. (2013). Upaya Meningkatkan Kemampuan Motorik Halus Anak Melalui Kegiatan Finger painting Di Pos Paud Mekar Lestari Pokak Ceper Klaten Tahun Ajaran 2012/2013. 7. Diakses tanggal 3 Juni 2016

Nursalam. (2014). Metodologi Penelitian Ilmu Keperawatan. Jakarta: Salemba Medika.

Patmonodewo, S. (2008). Pendidikan Anak Prasekolah. Jakarta: Rineka Cipta.

Pamadhi. (2008). Seni Keterampilan Anak. Jakarta: Universitas Terbuka

Partiyem. (2014). Meningkatkan Kemampuan Motorik Halus. Meningkatkan Kemampuan Motorik Halus Dengan Kegiatan Bermain Plastisin Kelompok B PAUD Istiqomah Sumber Bening Kecamatan Selupu Rejang. Diakses tanggal 30 Desember 2015.

Soetjiningsih. (2013). Tumbuh Kembang Anak. Edisi 2. Jakarta: EGC.

Sujiono, B. (2009). Metode Pengembangan Fisik. Jakarta: Universitas Terbuka.

Sulistyawati, A. (2014). Deteksi Tumbuh Kembang Anak. Jakarta: Salemba Medika.

Vitamami, L. (2013). Peningkatan Kemampuan Motorik Halus Dengan Finger Painting Pada Kelompok A2 RA BABUSSALAM Krian Sidoarjo. Diakses tanggal 4 Juni 2016 